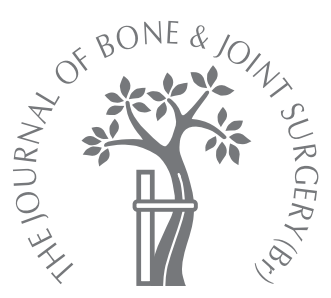

\title{
A cemented mobile-bearing total knee replacement prevents periprosthetic loss of bone mineral density around the femoral component
}

\author{
A MATCHED COHORT STUDY
}

Y. Minoda,

M. Ikebuchi,

A. Kobayashi,

H. Iwaki,

F. Inori,

H. Nakamura

From Osaka City

University Graduate

School of Medicine,

Osaka, Japan

Bone mineral density (BMD) around the femoral component has been reported to decrease after total knee replacement (TKR) because of stress shielding. Our aim was to determine whether a cemented mobile-bearing component reduced the post-operative loss of BMD. In our study 28 knees receiving a cemented fixed-bearing TKR were matched with 28 receiving a cemented mobile-bearing TKR. They underwent dual-energy x-ray absorptiometry, preoperatively and at three weeks and at three, six, 12, 18 and 24 months post-operatively. The patients were not taking medication to improve the BMD.

The pre-operative differences in the BMD of the femoral neck, wrist, lumbar spine and knee in the two groups were not significant. The BMD of the femur decreased postoperatively in the fixed-bearing group, but not the mobile-bearing group. The difference in the post-operative change in the BMD in the two groups was statistically significant $(p<0.05)$ at 18 and 24 months.

Our findings show that a cemented mobile-bearing TKR has a favourable effect on the BMD of the distal femur after TKR in the short term. Further study is required to determine the long-term effects.

After total knee replacement (TKR), the bone mineral density (BMD) decreases around the cemented and cementless femoral component. ${ }^{1-7}$ Stress shielding is thought to be the main cause of this bone loss $^{7}$ and it has been reported that the design of the articulating surface affects the change in BMD. ${ }^{3}$ TKRs with posteriorly stabilised inserts have more reduction in BMD than those with other types of insert, such as cruciate-retaining implants. ${ }^{3}$ The mobile-bearing TKR is designed to maximise conformity between the articulating components and to minimise constraint. It has been suggested that the mobility of the polyethylene insert reduces transmission of stress to the prosthesis-bone interface. ${ }^{8,9}$ However, there have been no studies which have focused on the changes in BMD after implantation of a mobile-bearing posteriorly stabilised TKR. Our hypothesis was that a cemented mobilebearing TKR would decrease the postoperative loss of BMD around the femoral component. We compared the post-operative BMD of a group of patients who underwent a conventional cemented fixed-bearing posteriorly stabilised TKR (NexGen LPS-flex; Zimmer, Warsaw, Indiana) with a group who underwent cemented mobile-bearing TKR (PFC Sigma RP; Depuy, Warsaw, Indiana).

\section{Patients and Methods}

Between June 2004 and September 2005, 32 primary TKRs were performed in 32 patients using a cemented fixed-bearing (NexGen LPS-flex) posterior-stabilised prosthesis. Three patients died of unrelated causes during the follow-up period and one failed to have measurement of his BMD at two weeks after the operation. This left 28 patients in this group who were available for clinical and radiological reviews.

At the same time 76 patients who had undergone a primary TKR using a cemented mobile-bearing PFC Sigma RP posteriorly stabilised prosthesis were identified. From this series, 28 (28 knees) were matched with respect to gender, age, body-weight, height, diagnosis and date of surgery with the patients with a fixed-bearing prosthesis to obtain matched pairs. We compared the BMD around the femoral component in both groups. Our study was approved by our Institutional Review Board and all the patients gave informed consent. 
All the TKRs were performed by the senior author (AK) through a standard midline incision with a medial parapatellar approach. The posterior cruciate ligament was resected. Tibial resection was performed, with an attempt to remove $10 \mathrm{~mm}$ from the articular surface perpendicular to the shaft of the tibia in the coronal plane. According to the manufacturer's recommendation, the intended posterior slope of the resection was $0^{\circ}$ for the PFC Sigma RP and $7^{\circ}$ for the NexGen LPS-Flex implant. Distal femoral resection removed a thickness of bone equal to that of the femoral component perpendicular to the mechanical axis of the femur. The size of the femoral component was determined using a sizer with an anterior reference system. The femoral component was introduced in $3^{\circ}$ of external rotation in relation to the posterior condyles. Osteophytes on the posterior aspect of the femur were removed. Ligamentous balancing was then performed. The patella was resurfaced in all the knees. All the femoral components were inserted with cement (Simplex P; Stryker, Mahwah, New Jersey) after thorough pulsed lavage. The drain was removed and patients were mobilised on the first post-operative day.

Clinical and radiological evaluation was performed preoperatively and at 24 months post-operatively by an author $(\mathrm{YM})$ who was not involved in any of the operations. Clinical evaluation was performed using the Knee Society score $^{10}$ and measurement of the range of movement of the knee. ${ }^{11}$ Radiological evaluation was performed using anteroposterior, lateral and skyline views with the knees flexed to $45^{\circ}$. Radiolucent lines were evaluated.

Dual-energy x-ray absorptiometry (DXA; QDR 4500A; Hologic, Waltham, Massachusetts) was used to measure the BMD. Standard scans of the L2-4 vertebrae, the ipsilateral femoral neck and the ipsilateral forearm were obtained pre-operatively and scans of the lumbar spine were also obtained at 24 months after the operation. The density in the distal part of the femur was measured at two weeks pre-operatively and at two weeks and at three, six, 12,18 and 24 months after the operation. The distal part of the femur was divided into three regions of interest (ROI) as follows: the anterior (ROI 1), the central (ROI 2) and the posterior (ROI 3) (Fig. 1).

Statistical analysis. The age, body-weight, height, pre- and post-operative Knee Society score ${ }^{10}$ and the pre-operative BMD in the lumbar spine, hip, forearm and knee in the two groups were compared using the Mann-Whitney U test. Gender and the pre-operative diagnosis in the two groups were compared using the chi-squared test or Fisher's exact test. The Mann-Whitney U test was also used to compare the relative changes in the BMD at three, six, 12, 18 and 24 months in the two groups in each stratum. The BMDs in each ROI at two weeks and at three, six, 12, 18 and 24 months after the operation in all the knees was compared using the paired $t$ test. A p-value $\leq 0.05$ was considered to be significant.

For the evaluation of reproducibility, DXA measurements were repeated twice in ten patients with an interval of one to seven days. The mean absolute value of the

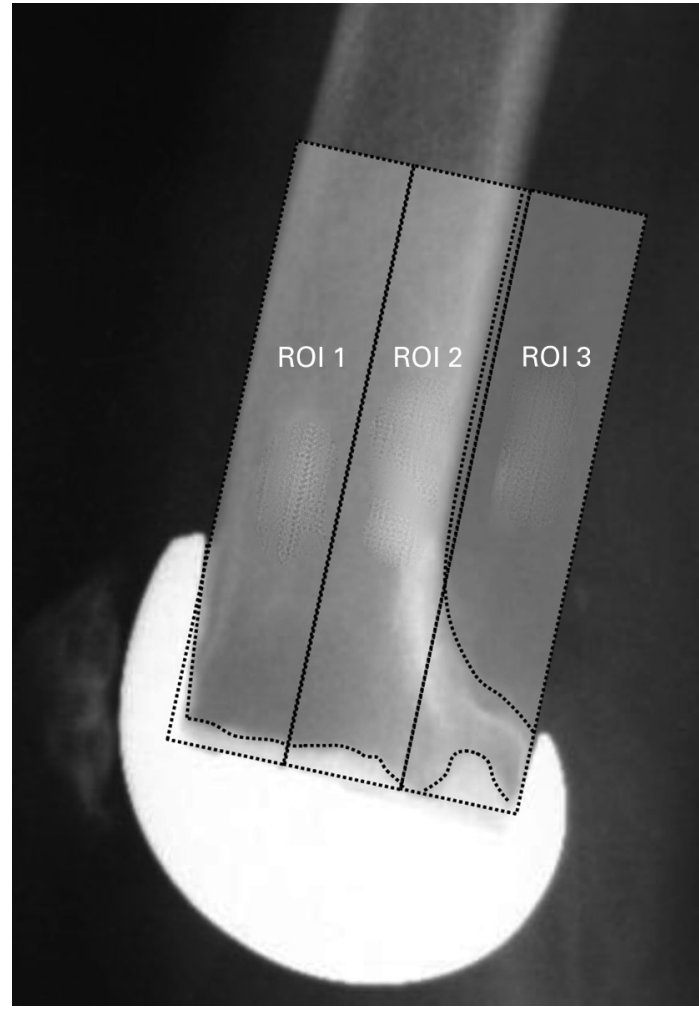

Fig. 1

Radiograph showing the bone mineral density measurements performed in the lateral projection in the distal part of the femur. Range of interest (ROI) 1 is the anterior third of the distal femur, ROI 2 the central third and ROI 3 the posterior.

difference was $0.05 \mathrm{~g} / \mathrm{cm}^{2}$ (95\% confidence interval (CI) 0.03 to +0.13$)$ at ROI $1,0.08 \mathrm{~g} / \mathrm{cm}^{2}(95 \%$ CI 0.01 to 0.15$)$ at ROI 2 and $0.05 \mathrm{~g} / \mathrm{cm}^{2}(95 \% \mathrm{CI}-0.02$ to +0.12$)$ at ROI 3. Intraclass correlation coefficients were $0.90,0.89$, and 0.99 for ROIs 1, 2 and 3, respectively. Power analysis showed that a sample size of 20 would be required to establish significance with $\alpha=0.05$ and with a power of 0.8 .

\section{Results}

None of the differences in pre-operative data (gender, age, body-weight, height, diagnosis, Knee Society score, range of movement) or the pre-operative BMD of the lumbar spine, hip, forearm and knee in the two groups was significant (Table I). In addition, at 24 months after operation, the differences in the Knee Society score, the range of movement of the knee, and the BMD in the lumbar spine in the two groups were not significant (Table II). No knee exhibited radiolucent lines.

In the fixed-bearing group, the BMD around the femoral component (ROI 1 to 3 ) decreased significantly post-operatively, but in the mobile-bearing group it did not (Table III). In ROI 3, the BMD was significantly increased at 12 months post-operatively $(p=0.047)$ in the mobile-bearing group. The difference between the pre-operative and the 24-month post-operative BMD in the lumbar spine was not 
Table I. Details of the pre-operative parameters in both groups

\begin{tabular}{|c|c|c|c|}
\hline Parameters $^{*}$ & Fixed-bearing & Mobile-bearing & p-value \\
\hline Mean (range) age at operation in years & 74.1 (57 to 85$)$ & 71.6 (57 to 83 ) & 0.136 \\
\hline \multicolumn{4}{|l|}{ Gender } \\
\hline$M: F$ & $6: 22$ & $6: 22$ & 1.000 \\
\hline Mean (range) body weight in $\mathrm{kg}$ & 55.6 (33 to 79$)$ & 59.1 (42 to 79 ) & 0.198 \\
\hline Mean (range) height in $\mathrm{cm}$ & 149.6 (135 to 169 ) & $151.8(137$ to 172$)$ & 0.255 \\
\hline \multicolumn{4}{|l|}{ Diagnosis } \\
\hline OA:RA & $26: 2$ & $26: 2$ & 1.000 \\
\hline \multicolumn{4}{|l|}{$\begin{array}{l}\text { Mean (range) Knee Society score } \\
\text { (points) }\end{array}$} \\
\hline Knee & $37.6(20$ to 51$)$ & 40.6 (20 to 60$)$ & 0.186 \\
\hline Function & 43.5 (20 to 70$)$ & 44.3 (20 to 65$)$ & 0.094 \\
\hline \multicolumn{4}{|l|}{ Mean (range) range of movement $\left({ }^{\circ}\right)$} \\
\hline Extension & $-10.5(-30$ to 51$)$ & $-11.6(-40$ to 0$)$ & 0.518 \\
\hline Flexion & 120.5 (80 to 140 ) & 121.4 (80 to 145$)$ & 0.682 \\
\hline \multicolumn{4}{|l|}{ Mean (range) BMD in $\mathrm{g} / \mathrm{cm}^{2}$} \\
\hline Lumbar spine & $0.937(0.629$ to 1.332$)$ & $0.874(0.681$ to 1.169$)$ & 0.359 \\
\hline Hip & $0.746(0.453$ to 1.018$)$ & $0.772(0.558$ to 1.108$)$ & 0.579 \\
\hline Forearm & $0.445(0.351$ to 0.604$)$ & $0.433(0.328$ to 0.575$)$ & 0.533 \\
\hline Knee (ROI 1) & $0.718(0.360$ to 1.348$)$ & $0.724(0.366$ to 1.500$)$ & 0.736 \\
\hline Knee (ROI 2) & $0.747(0.356$ to 0.910$)$ & $0.755(0.370$ to 0.869$)$ & 0.966 \\
\hline Knee (ROI 3) & $1.160(0.263$ to 0.841$)$ & $1.063(0.236$ to 0.868$)$ & 0.156 \\
\hline
\end{tabular}

Table II. Details of the post-operative parameters at 24 months after operation in both groups

\begin{tabular}{|c|c|c|c|}
\hline Parameters & Fixed-bearing & Mobile-bearing & p-value \\
\hline \multicolumn{4}{|c|}{ Mean (range) Knee Society score } \\
\hline Knee & 95.8 (78 to 100$)$ & 93.8 (83 to 100$)$ & 0.144 \\
\hline Function & 80.1 (45 to 100$)$ & $86.3(65$ to 100$)$ & 0.114 \\
\hline \multicolumn{4}{|c|}{ Mean (range) range of movement $\left({ }^{\circ}\right)$} \\
\hline Extension & $-2.0(-10$ to 0$)$ & $-2.5(-30$ to 0$)$ & 0.857 \\
\hline Flexion & $125.0(105$ to 140$)$ & $125.5(100$ to 140$)$ & 0.676 \\
\hline \multicolumn{4}{|c|}{ Mean (range) $\mathrm{BMD}^{\dagger}$ in $\mathrm{g} / \mathrm{cm}^{2}$} \\
\hline Lumbar spine & 0.881 (0.636 to 1.462$)$ & $0.946(0.690$ to 1.165$)$ & 0.903 \\
\hline
\end{tabular}

significant or in the fixed-bearing $(\mathrm{p}=0.892)$ or the mobilebearing group $(\mathrm{p}=0.604)$.

The relative change in the BMD in ROI 1 at 24 months was $-14.9 \% \quad(S D 17.2)$ in the fixed-bearing group $(\mathrm{p}<0.001)$ and $10.5 \%$ (SD 26.0) in the mobile-bearing group. The relative change in the BMD in ROI 2 at 24 months was $-8.7 \%$ (SD 19.9) in the fixed-bearing group $(\mathrm{p}=0.027)$ and $8.1 \%$ (SD 30.7) in the mobile-bearing group. In ROI 3 at 24 months it was $-0.7 \%$ (SD 18.9) in the fixed-bearing group $(\mathrm{p}=0.037)$ and $9.7 \%(\mathrm{SD} 23.9)$ in the mobile-bearing group (Fig. 2). The difference in the relative change in the BMD between the two groups was statistically significant in ROI 1 at 18 and 24 months, in ROI 2 at 12, 18 and 24 months and in ROI 3 at three, six, 12, 18 and 24 months (Fig. 2).

\section{Discussion}

Previous studies have shown a decrease in the BMD in the distal femur after TKR, regardless of the method of fixation (cemented or cementless) or if posteriorly stabilised or cruciate-retaining design were used. ${ }^{1-7}$ This decrease is most obvious during the first six months with a magnitude as high as $57 \%,{ }^{7}$ especially around the anterior femoral flange. ${ }^{5,7}$ It remains substantial with a mean of $5 \%$ per year, up to two 
Table III. Details (mean, SD) of post-operative bone mineral density $\left(\mathrm{g} / \mathrm{cm}^{2}\right)$ values in the distal femur in both groups

\begin{tabular}{|c|c|c|c|c|}
\hline & Fixed-bearing & p-value ${ }^{*}$ & Mobile-bearing & p-value \\
\hline \multicolumn{5}{|l|}{ ROI 1} \\
\hline 2 wks & $0.92(0.19)$ & & $0.99(0.21)$ & \\
\hline 3 mths & $0.88(0.21)$ & 0.113 & $0.98(0.19)$ & 0.757 \\
\hline 6 mths & $0.80(0.18)$ & $0.014^{\dagger}$ & $0.95(0.20)$ & 0.665 \\
\hline 12 mths & $0.81(0.17)$ & $0.002^{\ddagger}$ & $0.95(0.17)$ & 0.314 \\
\hline 18 mths & $0.78(0.19)$ & $<0.001^{\S}$ & $0.95(0.20)$ & 0.650 \\
\hline 24 mths & $0.77(0.19)$ & $<0.001^{\S}$ & $1.05(0.18)$ & 0.184 \\
\hline \multicolumn{5}{|l|}{ ROI 2} \\
\hline 2 wks & $1.16(0.32)$ & & $1.09(0.26)$ & \\
\hline 3 mths & $1.06(0.23)$ & 0.145 & $1.11(0.27)$ & 0.347 \\
\hline 6 mths & $0.95(0.23)$ & $0.019^{\dagger}$ & $1.06(0.20)$ & 0.882 \\
\hline 12 mths & $0.88(0.27)$ & $<0.001^{\S}$ & $1.11(0.24)$ & 0.451 \\
\hline 18 mths & $0.93(0.22)$ & $<0.001^{\S}$ & $1.06(0.21)$ & 0.451 \\
\hline 24 mths & $1.03(0.17)$ & $0.034^{\dagger}$ & $1.12(0.27)$ & 0.539 \\
\hline \multicolumn{5}{|l|}{ ROI 3} \\
\hline 2 wks & $1.45(0.26)$ & & $1.29(0.23)$ & \\
\hline 3 mths & $1.35(0.27)$ & $0.006^{\ddagger}$ & $1.33(0.28)$ & 0.223 \\
\hline 6 mths & $1.22(0.26)$ & $<0.001^{\S}$ & $1.31(0.21)$ & 0.638 \\
\hline 12 mths & $1.19(0.27)$ & $<0.001^{\S}$ & $1.37(0.23)$ & $0.047^{*}$ \\
\hline 18 mths & $1.32(0.25)$ & $0.010^{\dagger}$ & $1.34(0.21)$ & 0.583 \\
\hline 24 mths & $1.42(0.26)$ & 0.527 & $1.39(0.26)$ & 0.120 \\
\hline
\end{tabular}

* paired $t$-test

† significantly different at $p<0.005$

‡ significantly different at $p<0.01$

$\S$ significantly different at $p<0.001$

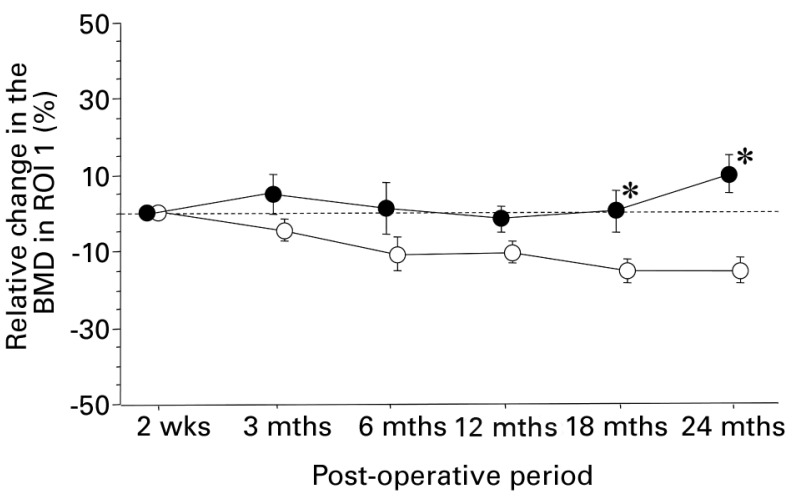

Fig. 2a

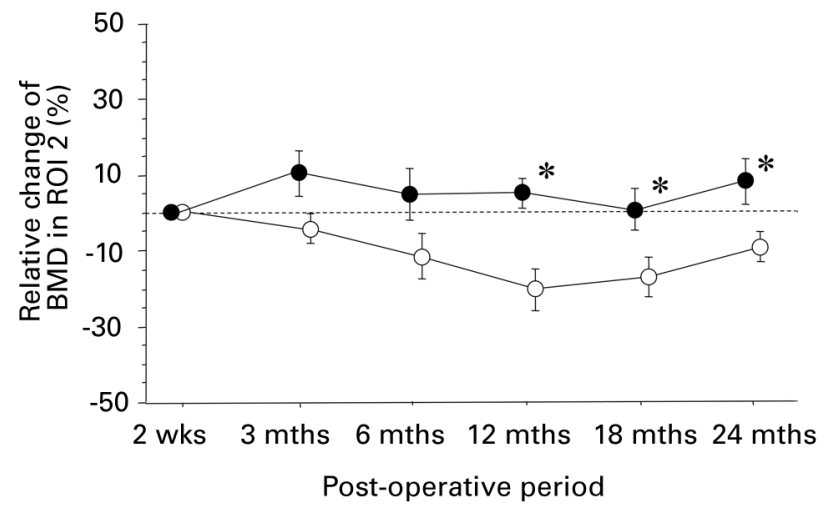

Fig. 2b

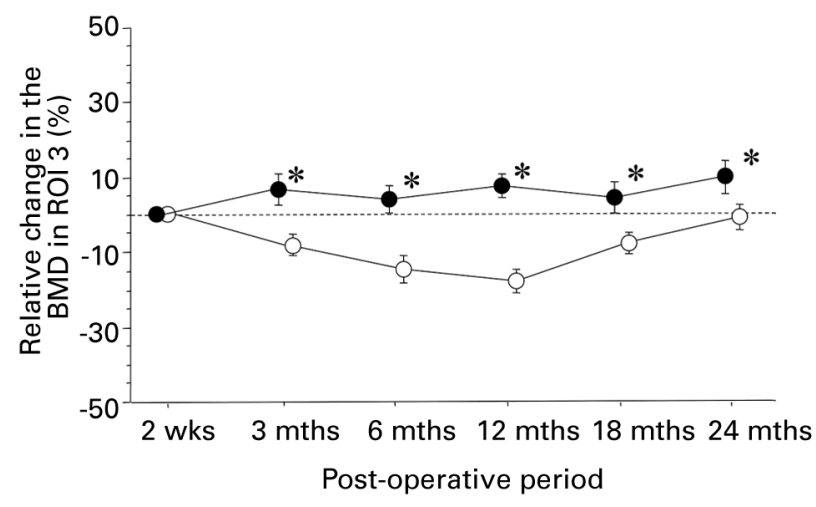

Fig. 2c

Graph showing the relative changes in bone mineral density (BMD) (mean, standard error). Range of interest (ROI) 1 to $3(\%)$ in the distal femur. The black dots represent the mobile-bearing component and the white dots the fixed-bearing component. Figure $2 a-$ The differences in the relative change in $\mathrm{BMD}$ in $\mathrm{ROI} 1$ were significantly less with the mobile-bearing component than in the fixed-bearing component at 18 and 24 months $(* p<0.05)$. Figure $2 b-$ The differences in relative change in the BMD in ROI 2 were significantly less in the mobile-bearing component than in the fixed-bearing component at 12,18 and 24 months $(* \mathrm{p}<0.05)$. Figure $2 \mathrm{c}-$ The differences in the relative change in the BMD in ROI 3 were significantly less in the mobile-bearing component than in the fixed-bearing component at 3 to 24 months. ( ${ }^{*} p<0.05$ ).

cruciate-retaining design were used. The magnitude of BMD decrease around the tibial component was similar between each design. However, the magnitude of BMD 
decrease around the femoral component was larger in the posteriorily stabilised design.

There are some limitations to our study. First, although the improvement in the BMD around the femoral component in the mobile-bearing group was suspected to yield better fixation of the components and to reduce the risk of periprosthetic fracture, ${ }^{8,9}$ the relationship between the loss of BMD in the distal femur and the clinical results has yet to be proven. Secondly, the femoral components used in the two groups were produced by different manufacturers. However, we suspect that the minor differences in these had much less effect on our results than the difference in the type of mechanism for the following reasons. Both types of femoral component were made of a cobalt-chrome alloy, and fixation was performed with the same bone-cement product (Simplex P). The designs of both femoral component were of the posteriorly stabilised type and very similar.

This is the first study on the BMD after cemented TKR which compares fixed-bearing and mobile components. We found that the knees with a cemented mobile-bearing component prevented post-operative loss of BMD around the femoral component compared with a cemented fixed-bearing component. The changes in the BMD in knees with a cemented mobile-bearing component beyond two years are currently unknown. Additional follow-up information would be required to determine the long-term clinical benefits of the use of the cemented mobile-bearing mechanism in TKR.

We wish to thank Dr K. Takaoka and Dr Y. Hashimoto for their assistance with this study.

No benefits in any form have been received or will be received from a commercial party related directly or indirectly to the subject of this article.

\section{References}

1. Abu-Rajab RB, Watson WS, Walker B, et al. Peri-prosthetic bone mineral density after total knee arthroplasty: cemented versus cementless fixation. J Bone Joint Surg [Br] 2006;88-B:606-13.

2. Wang CJ, Wang JW, Ko JY, Weng LH, Huang CC. Three-year changes in bone mineral density around the knee after a six-month course of oral alendronate following total knee arthroplasty: a prospective, randomized study. J Bone Joint Surg [Am] 2006;88-A:267-72.

3. Saari T, Uvehammer J, Carlsson LV, Regnér L, Kärrholm J. Posterior stabilized component increased femoral bone loss after total knee replacement: 5 -year followup of 47 knees using dual energy x-ray absorptiometry. Knee 2006;13:435-9.

4. Wang CJ, Wang JW, Weng LH, et al. The effect of alendronate on bone mineral density in the distal part of the femur and proximal part of the tibia after total knee arthroplasty. J Bone Joint Surg [Am] 2003;85-A:2121-6.

5. van Loon CJ, Oyen WJ, de Waal Malefijt MC, Verdonschot N. Distal femoral bone mineral density after total knee arthroplasty: a comparison with general bone mineral density. Arch Orthop Trauma Surg 2001;121:282-5.

6. Karbowski A, Schwitalle M, Eckardt A, Heine J. Periprosthetic bone remodelling after total knee arthroplasty: early assessment by dual energy $\mathrm{x}$-ray absorptiometry. Arch Orthop Trauma Surg 1999;119:324-6.

7. Seki T, Omori G, Koga Y, et al. Is bone density in the distal femur affected by use of cement and by femoral component design in total knee arthroplasty? J Orthop Sci 1999;:180-6.

8. Garling EH, Valstar ER, Nelissen RG. Comparison of micromotion in mobile bearing and posterior stabilized total knee prostheses: a randomized RSA study of 40 knees followed for 2 years. Acta Orthop 2005;76:353-61.

9. Insall JN, Aglietti P, Baldini A, Easley E. Meniscal-bearing knee replacement. In: Insall JN, Scott WN, eds. Surgery of the knee. Vol. 2. Third ed. Philadelphia: ChurchillLivingstone, 2001:1717-38.

10. Insall JN, Dorr LD, Scott D, Scott WN. Rationale of the Knee Society clinical rating system. Clin Orthop 1989;248:13-14.

11. Kim YH, Sohn KS, Kim JS. Range of motion of standard and high-flexion posterior stabilized total knee prostheses: a prospective, randomized study. J Bone Joint Surg [Am] 2005;87-A:1470-5.

12. Saari T, Uvehammer J, Carlsson L, Regnér L, Kärrholm J. Joint area constraint had no influence on bone loss in proximal tibia 5 years after total knee replacement. J Orthop Res 2007;25:798-803. 